\title{
O espanhol e ensino: crenças de estudantes e professores sobre história e diversidade da língua no contexto brasileiro
}

Alexandra Gomes dos Santos*

\begin{abstract}
Resumo
A difícil realidade e os constantes desafios que fazem parte do sistema educativo brasileiro pedem um novo perfil de educador e uma formação que o respalde. É necessária a formação de docentes competentes, comprometidos e capazes de ensinar em situações de constantes mudanças e com alunos cultural, social e linguisticamente heterogêneos. Essa representação engloba diversos tipos de conhecimento e funções referentes às tradicionalmente assumidas, que mostram a necessidade de uma formação de professores mais completa e que revele ao educando, em um contexto multi e intercultural, a diversidade da língua espanhola. Na prática, o que acontece, contrariamente ao proposto e esperado, é que todo processo social, cultural e histórico, que deveria ser posto no centro dos programas de formação de professores, é ocultado em prol de um imaginário, ainda muito propagado, de que a língua espanhola é única e homogênea. O presente artigo tem como objetivo averiguar de que forma estudantes e professores, formados e em formação, compreendem questões sobre a diversidade da língua espanhola, como a opção da variedade da língua e as crenças que permeiam o ensino-aprendizagem da mesma. Para isso, objetivou-se também fazer uma revisão de alguns trabalhos que trataram sobre a diversidade e o ensino da língua no Brasil nos últimos vinte anos. Apontou-se para o fato de que a diversidade do espanhol é ainda mal trabalhada nos cursos de formação de professores, gerando a manutenção da preferência pelo espanhol europeu e provocando estereótipos bastante equivocados sobre a língua.

Palavras-Chave: ensino de espanhol, diversidade linguística, crenças, formação de professores, espanhol no Brasil.
\end{abstract}

\section{Spanish and teaching: students and teachers' beliefs about the history and diversity of the language in the Brazilian context}

Abstract

The difficult reality and the constant challenges that are part of the Brazilian educational system demand a new profile of educator and a training that supports it. It is necessary the formation of competent and committed teachers who are able to teach in situations of constant changes relating to students who are culturally, socially and linguistically heterogeneous. This representation encompasses several types of knowledge and functions related to the traditionally assumed practice, which shows the need for a more complete teacher education and that reveals to the learner, in a multi and intercultural context, the diversity of the Spanish language. In practice, what happens, opposite to what is proposed and expected, is that every social, cultural and historical process that should be put in the center of teacher training programs is hidden in favor of an imaginary and still widely propagated idea that the Spanish language is unique and homogeneous. This article aims to find out how students and teachers understand questions about the diversity of the Spanish language, such as the choice of the variety of the language and the beliefs that permeate teaching-learning. The purpose of this study is to review some of the papers that deal with the diversity and teaching of language in Brazil in the last 20 years. It was pointed out that the diversity of Spanish is still poorly handled in teacher training courses, which leads to the maintenance of the preference for European Spanish and reinforces stereotypes about the language.

Keywords: teaching of Spanish, linguistic diversity, beliefs, teacher training, spanish in Brazil.

*Doutoranda do Programa de Pós-Graduação em Língua e Cultura, do Instituto de Letras da Universidade Federal da Bahia. E-mail: prof.legomes@gmail.com. 


\section{Palavras iniciais: contextualizando o problema}

A língua espanhola é língua oficial em mais de 20 países, chegando ao número de mais de 400 milhões de hispano-falantes (MORENO FERNÁNDEZ, 2000; AGOSTO, 2006). O espanhol possui uma geografia que se estende por quase um continente e se faz presente em outros três. Segundo Andión Herrero (2008), é a segunda língua com mais falantes nativos no mundo, sendo antecedida apenas pela língua chinesa. Apesar dos avanços nos estudos sociolinguísticos, ainda há, no imaginário gerado pelo senso comum, a ideia de que o espanhol da Espanha e o espanhol da América são duas realidades linguísticas bastante diferentes. Fontanella de Weinberg (1993) salienta também que o espanhol da Espanha e o espanhol da América não podem ser considerados dois blocos linguísticos opostos entre si. Sobre a diversidade do espanhol, Lope Blanch (1989) salienta:

La lengua española sigue siendo el sistema lingüístico de comunicación
común a veinte naciones, no obstante, las particulares diferencias -léxicas,
fonéticas y, en menor grado, morfosintácticas- que esmaltan el uso en unas y
otras. Diferencias que se producen entre todos esos veinte países, sin
permitirnos establecer dos grandes modalidades bien contrastadas -española
y americana- por cuanto que, además, existe mayor afinidad entre algunas
modalidades americanas y españolas que entre ciertas modalidades
hispanoamericanas entre sí (LOPE BLANCH, 1989, p. 29).

O ensino-aprendizagem da língua espanhola e, atrelado a isso, diversas pesquisas sobre a diversidade no ensino da língua no Brasil, tem sua história marcada por três momentos bem demarcados. O primeiro, antes da década de 1990, foi marcado pela crença de que, por conta da proximidade com os países de fala hispânica, aprender espanhol era uma tarefanada complicada. O segundo momento foi a criação do Mercosul, que, como bloco econômico e político, promoveu o movimento que integrou e fez revolução no cenário nacional no ensino de língua espanhola, acontecimento que desencadeou políticas específicas para essa realidade. Como resultado, essa mudança culminou no terceiro momento, que, nos anos 2000, pode motivar políticas específicas voltada à educação básica, como a implantação da Lei 11.161, de 5 de agosto de 2005 , que fez do espanhol uma disciplina de oferta obrigatória no Ensino Médio e optativa no Ensino Fundamental, e a criação das Orientações Curriculares para o Ensino Médio (OCEM), em 2006, que possuem um capítulo exclusivamente dedicado ao ensino da língua espanhola. Com relação à diversidade do espanhol, as OCEM dizem: 
[...] Certamente a questão “Que Espanhol ensinar?” deve ser substituída por uma outra: como ensinar o Espanhol, essa língua tão plural, tão heterogênea, sem sacrificar as suas diferenças nem reduzi-las a puras amostragens sem qualquer reflexão maior a seu respeito? No entanto, aquela primeira pergunta, por diferentes razões, ainda se mantém (OCEM, 2006, p. 134).

No final da década de 1990, segundo Bugel (1999), tinha-se uma procura maior pelos países vizinhos e esse era um dos principais gatilhos motivadores na busca pela aprendizagem da língua espanhola. No atual contexto brasileiro, dezessete anos depois do trabalho de Bugel (1999), parece haver uma desconexão das políticas linguísticas relacionadas ao ensino da língua com o objetivo inicial, a proximidade com os países latino-americanos.

O ensino de língua espanhola a partir de uma visão que foca a variedade europeia vai no caminho contrário às políticas desenvolvidas ao longo desses anos. A invisibilidade dos países latino-americanos, discutida em Bugel (1999), no que tange ao ensino do espanhol no cenário brasileiro ainda permanece, como se percebe em ZolinVesz (2013):

\begin{abstract}
Por isso, penso que a questão ética da visibilidade dos países da América Latina seja o ponto principal a ser resguardado. Afinal de contas, que sentido teria a homologação de uma lei que obriga a oferta da língua espanhola nas escolas em nosso país, a não ser que o objetivo se case com o fortalecimento da integração regional, principalmente no sentido de dotar um papel político ao ensino do espanhol na educação brasileira - o de elemento de integração regional? (ZOLIN-VESZ, 2013, p. 61).
\end{abstract}

De modo geral, o ensino de uma língua tem como base modelos constituídos por variedades de prestígio. No caso da língua espanhola no contexto brasileiro, o poder econômico, relacionado à tradicional representação de "tudo que vem da Europa é superior", vem determinando a variedade padrão escolhida no ensino do espanhol como língua estrangeira (ZOLIN-VESZ, 2013). A opção por uma variedade europeia como referência para o ensino da língua, assim como o fato de falantes americanos por vezes recorrerem a ela como modelo ideal, possui razões econômicas, históricas e políticas que fazem referência a anos de políticas linguísticas direcionadas para a ascensão de um imaginário de unidade linguística, na qual a diversidade foi, muitas vezes, negligenciada. 
Nesse contexto, este artigo tem como objetivo apresentar alguns trabalhos que se debruçaram no debate sobre as crenças e representações da diversidade no ensino de espanhol no Brasil, comparando esses trabalhos, que foram feitos em diversas regiões do país, com o trabalho de Santos (2016), em que pude pesquisar sobre a situação das variedades da língua espanhola em um curso de formação de professores de espanhol em Salvador. Por fim, tecerei algumas considerações finais sobre o tema.

\section{Crenças sobre a variedade do espanhol no Brasil}

Para iniciar a discussão sobre o ensino de língua espanhola no contexto brasileiro, apresento o trabalho de Bugel (1999), que evidencia que o cenário do ensino de espanhol em São Paulo demonstrava a permanência dos preconceitos mais comuns referente às variedades americanas, fato que afeta o processo de ensino-aprendizagem da língua. Segundo Bugel (1999):

\footnotetext{
Num dos institutos pesquisados, com forte ligação com a tradição espanhola de ensino da língua, o coordenador e professores latino-americanos entrevistados defendem a "preservação da unidade linguística" como sua intenção principal. No entanto, a partir dessa intenção, apresenta-se um dilema para os professores na hora de falar na sala de aula, porque é preciso escolher uma variante. Questionados acerca da resolução do dilema que eles mesmos colocam, os professores admitem que a possibilidade de escolha é de fato muito relativa, porque eles já têm uma variante, que é a materna de cada um. A solução aplicada para resolver a situação, neste instituto, é não exigir que os alunos usem a variante do professor, direcionando-os para o uso do "usual" (BUGEL, 1999, p. 78).
}

Pode-se constatar, portanto, referente às concepções dos professores acerca das variedades de espanhol, uma superação formal da crença que coloca a variedade europeia do espanhol como padrão, ou seja, uma inicial tomada de consciência de que existem outras variedades da língua espanhola. O ponto de tensão se concentra, no entanto, no fato de que, apesar de terem certa consciência da variação, existe uma falta de conhecimento linguístico no que se refere às variedades, tanto americanas, quanto europeias. Segundo Bugel (1999), a falta de informação dos professores entrevistados sobre as particularidades das variedades latinas é um fato que impede sua defesa e uma real utilização em sala de aula. O resultado disso é a utilização de um espanhol chamado "neutro", que se comprovou ser, em grande maioria, coincidente ao espanhol peninsular. Desse modo, ainda que as variedades maternas desses professores incluídos 
na pesquisa de Bugel (1999) não sejam consideradas por eles "incorretas", não há argumentação forte o suficiente para usá-las em sala, em lugar da variedade europeia utilizada nos livros didáticos.

Irala (2004) é o segundo trabalho trazido para essa discussão. Ao investigar qual variedade da língua espanhola preferem os alunos e professores em uma região da fronteira entre Brasil e o Uruguai, Irala (2004) encontra as seguintes afirmações (destaques feitos pela autora):
Algumas falas merecem considerações especiais (grifos feitos por mim):
1) Espanhol da Espanha, porque é uma língua melhor de ser trabalhada com o aluno.
2) Prefiro o Espanhol da Espanha. Acho mais claro e muito mais bonito.
3) Da Espanha, porque é mais clássico.
4) Prefiro o Espanhol da Espanha, porque é o mais puro, pois é a língua-mãe. O Espanhol da América já teve muitas influências de outros povos e costumes.

5) Da Espanha, porque além de ter aprendido assim, penso que é mais sonoro.

6) Nos livros didáticos vem o Espanhol da Espanha, mas vivendo nós na fronteira com o Uruguai, não podemos ignorar este fato. Devemos apresentar aos nossos alunos as pronúncias dos dois idiomas e principalmente os modismos.

7) Da Espanha. Porque é o único que aprendi até agora.

8) Para trabalhar com as crianças, o da América, porque faz parte da realidade deles.

9) Da Espanha, porque é o mais divulgado nos meios de comunicação em geral.

10) América, pois são essas as pessoas que circulam pela nossa cidade e com elas é que podemos por em prática os conhecimentos de sala de aula. (IRALA, 2004. p. 109-110).

Sobre tais declarações, o que seria, concretamente, um espanhol mais puro? Por qual razão ainda se considera a variedade europeia na atualidade a língua "mãe"? Por que, por exemplo, o espanhol da Espanha seria melhor de ser trabalhado com estudantes numa região de fronteira com o Uruguai? A partir da pesquisa de Irala (2004), pode-se perceber que os professores preferem o espanhol peninsular, fato que entra em desacordo com a situação de região de fronteira na qual a pesquisa foi elaborada.

A conclusão dos dados apresenta a preferência dos alunos de graduação e professores em exercício pelo "Espanhol da metrópole" e reflete uma situação que foi imposta ao longo dos anos - o mito da língua espanhola peninsular "pura" e "prestigiada" -, sem que para isso tenham a real consciência dos fatores sócio históricos que atravessam essa questão. Quando os alunos e professores dizem preferir o espanhol 
da Espanha porque é a língua mãe, se esquecem que tanto o espanhol da América atual como o espanhol da Espanha atual são resultado das mudanças pelas quais passou o espanhol antigo. Outro ponto importante é que não levam em consideração os interesses econômicos e as políticas linguísticas da península, uma vez que

\begin{abstract}
A Espanha tem uma política clara de difusão do castelhano peninsular espalhada por todos os continentes, porque sabe o que representa, em termos de poder, a expansão de sua variante. A América, fragmentada em diversos países e com muitos problemas internos, não consegue estabelecer uma política clara que favoreça a difusão de suas diversas variedades, salvo algumas iniciativas isoladas de algumas universidades, mas com raro respaldo do mercado editorial para a sua difusão (IRALA, 2004, p. 117).
\end{abstract}

O terceiro trabalho é o de Murga (2007), que, ao pesquisar as atitudes de estudantes brasileiros de língua espanhola diante de algumas variedades da língua (variedades da Argentina, Chile, Cuba, Madri, México e Sevilha), encontrou disparidades no comportamento, assim como no resultado dos questionários da sua pesquisa, antes e depois de os estudantes serem submetidos à consciência sobre qual seria a variedade regional específica. Antes da tomada de consciência,

\begin{abstract}
As crenças mais destacáveis, no caso do falante 3 (mexicano), foram a simpatia e qualidade de voz. Com relação ao falante 2 (argentino), à 4 (sevilhana) e ao mexicano, os sujeitos participantes acharam o discurso desses falantes fácil de compreender, pois falavam mais pausado e com mais clareza. Quanto à falante 6 (Madrid), ao falante 5 (cubano) e à falante 1 (chilena), os sujeitos participantes da pesquisa consideraram a compreensão auditiva mais difícil, pois eles falavam mais rápido e com menos clareza, isso determinaria, portanto (em parte), a menor compreensibilidade dos falantes dessas variedades diatópicas (MURGA, 2007, p.73).
\end{abstract}

Com relação à atitude desses estudantes de Espanhol como língua estrangeira, no momento em que a origem regional foi revelada, observou-se uma mudança no comportamento e uma clara predileção pelas variedades europeias. Foram constatadas avaliações muito favoráveis correspondentes primeiramente à variedade da região de Sevilha e, em segundo lugar, à variedade de Madri. Observa-se, então, uma clara mudança de atitude quando comparada à atitude demonstrada quando ainda não havia sido revelada a origem, fato que expõe a acentuada valorização da variedade europeia, que recebeu como justificativa para a classificação de "muito agradável", respostas como "origem da língua", "bonito", "Espanhol-Espanhol mesmo", "Espanha 
desenvolvida", "Espanha é Europa", "realidade de primeiro mundo", “está por cima". Como salienta a autora:

Pode-se concluir que quando foi fornecida a informação sobre a origem
regional de cada um dos falantes, esta acabou (por meio da mediação de uma
série de fatores) influenciando as atitudes anteriores, e ocorreu uma clara
mudança quanto ao falante da variedade argentina e à falante de Madri. A
mudança de atitude observada com relação à falante de Madri corresponde às
crenças associadas à correção ou superioridade linguística da variedade
peninsular, assim como ao fato de a Espanha ser "Europa". No caso do
falante argentino, a atitude com uma nota mais negativa manifesta a presença
de crenças sobre o sotaque, considerado como carregado e não-bonito, além
de percepções estereotipadas que permanecem implícitas (MURGA, 2007, p.
74).

Em Santos (2016), busquei analisar, em comparação com o trabalho de Irala (2004) que, vale salientar, foi feito numa região de fronteira, o de Bugel e Santos (2007), na região de São Paulo, assim como o de Murga (2007), feito em Brasília, dentre outros que não foram citados neste trabalho, de que maneira professores em formação compreendem a variação da língua espanhola, trazendo para esse fim questões, como a opção da variedade da língua espanhola e as crenças que abarcam o ensino-aprendizagem da língua. Aplicou-se um questionário a 30 alunos, dos semestres iniciais e finais, dos cursos de licenciatura em Língua Espanhola da Universidade Federal da Bahia. A última questão, que foi subjetiva, teve por objetivo colher as justificativas para as questões objetivas que falavam sobre a variedade do espanhol no contexto brasileiro.

Neste trabalho, pude perceber um contexto contraditório, em que se tem a consciência de que as duas variedades do espanhol (tendenciosamente divididas na pesquisa em europeia e americana) são relevantes de serem aprendidas no contexto brasileiro, mas ainda estão fortemente influenciados pelo senso comum de que a variedade europeia é "mais fácil", "pura" e "melhor" de ser compreendida, como podemos inferir nas justificativas mais relevantes listadas abaixo:

1) O espanhol da Espanha tem onde se fundamentar, pois existe uma história por trás a ser contada e estudada.

2) Acho que deveriam ensinar todas as variações, apesar de achar o espanhol da Espanha melhor e mais fácil.

3) O espanhol da Espanha é mais compreensível.

4) O espanhol da Espanha é mais claro e o que mais ouço as pessoas falarem aqui. Não tenho preconceito, mas na Espanha o espanhol é mais bonito de se falar. 
5) Todas as variedades devem ser ensinadas no Brasil. Eu falo o espanhol da Espanha porque foi o único que aprendi.

6) Espanhol da Espanha ou da América não tem diferença. Todas as variantes devem ser respeitadas no Brasil.

7) Acho muito importante o estudo do espanhol com uma perspectiva heterogênea, focando sempre nas variações existentes na língua espanhola.

8) Respeitando a variedade, creio que o espanhol da Espanha é mais claro.

9) Prefiro o espanhol da Espanha porque entendo melhor e é mais bonito.

10) O espanhol como próprio da língua tem várias variantes já que são vários países que o falam (SANTOS, 2016, p.69, grifos da autora).

É possível perceber que respostas como "entendo melhor e é mais bonito", "mais bonito de se falar", "melhor e mais fácil", são evidências de que o senso comum sobre a variação da língua espanhola ainda é ponto dominante no Brasil. Respostas equivalentes foram encontradas na pesquisa de Irala (2004) e no trabalho de Bugel e Santos (2007), fato que confirma que o lapso temporal e os avanços no ensino de espanhol não mudaram a opinião referente à opção da variedade linguística da língua espanhola adotada no processo de ensino-aprendizagem no Brasil.

Dentre as justificativas encontramos as seguintes considerações relacionadas ao espanhol da América:

11) Sou a favor de um espanhol que não seja nem da Espanha, nem da América, que é misturado com a língua indígena, fato que dificulta $o$ entendimento aqui no Brasil.

12) Todas as línguas têm que ser ensinadas, mas o espanhol da Espanha é mais limpo, puro, porque o da América é misturado com as línguas indígenas e isso dificulta a compreensão.

13) Prefiro o espanhol neutro, nem da Espanha, nem da América, mas sem traços das línguas indígenas, porque isso complica (SANTOS, 2016, p.70, grifos da autora).

Essas considerações remetem ao trabalho de Bugel (1999) que comprovou que educadores nativos latino-americanos deixaram de lado suas variedades maternas com a justificativa da necessidade de adotar uma língua padrão que, segundo a autora, assemelha-se ao espanhol europeu. O fato é que, com relação à Espanha, não se pode desconsiderar os constantes movimentos migratórios ao longo da história, nem a presença das três línguas nacionais da península, que coexistem junto ao espanhol (o galego, o basco e o catalão), haja vista que, se as diferenciações existem dentro da própria Espanha, é extremamente aceitável que existam particularidades na língua 
falada no continente americano, que podem ser de diversos domínios: fonético, morfológico, sintático, léxico e semântico-discursivo.

Diante de tais questões, cabe questionar se os objetivos propostos para a implementação da língua espanhola no ensino no Brasil estão sendo realmente realizados, tendo em vista que, para além de ter preferência por uma ou por outra variedade, respostas como (1) (2) (3) (8) estão impregnadas de preconceito social, linguístico e histórico e reproduzidas, por vezes, como verdades absolutas no ambiente acadêmico.

As respostas dadas por esses alunos fazem referência direta à falta de trato com a variação linguística no ensino de Espanhol, especialmente nos cursos de formação de professores. $\mathrm{O}$ fato de o currículo dos cursos não trazer satisfatoriamente aspectos sobre a variação e história do espanhol, como analisei em Santos (2016), pode ter se refletido nas justificativas, que, vale ressaltar, são as considerações de professores em formação e que remetem a outras variáveis, como a escassez de políticas claras para a propagação do espanhol na conjuntura latina, assim como políticas que se adequem à necessidade de cada comunidade.

O professor, nesse contexto, precisa exercer um papel fundamental no processo de ensino-aprendizagem de espanhol como língua estrangeira, pois é ele quem orienta o aluno de acordo com suas reais necessidades. Segundo Ruiz (2004, p. 10), "El trabajo en la enseñanza/aprendizaje de una LE no puede estar previamente establecido sino que debe ser fruto del consenso, de las necesidades de comunicación de los aprendientes". Com isso, o professor deve conhecer a língua espanhola de modo que possa lidar com as múltiplas possibilidades de interesses dos seus alunos, fato que não significa que o professor precisa conhecer todas as variedades da língua, mas, isso sim, ter a consciência da diversidade do espanhol e de que a realização da língua é maior do que aquilo que efetivamente conhece.

\section{Considerações finais}

Neste artigo, foi levantada a problematização das crenças e representações sobre a diversidade linguística no ensino de espanhol no Brasil. Foi feita uma pequena revisão de alguns trabalhos que trataram a questão no Brasil nos últimos vinte anos. De modo geral, pode-se perceber nas respostas dadas pelos alunos a falta de tratamento adequado 
no que diz respeito à história e à variação da língua espanhola, assim como também foi constatado nos trabalhos utilizados neste artigo para contextualizar a pesquisa no cenário.

Nessas pesquisas, foi possível observar que, entre professores e estudantes, há uma preferência, fundamentada no senso comum, de que a variedade espanhola é a mais "pura" e "melhor" de ser ensinada no Brasil. Observa-se, também, que esses alunos não possuem conhecimento suficiente sobre os aspectos variáveis do América Latina, visto que a maioria deles acredita que o espanhol da América é constituído como um bloco homogêneo, onde todos falam a mesma variedade da língua.

É válido recordar que, em 2017, houve uma reforma no Ensino Médio, traduzida nos dispositivos legais, por meio da Lei Ordinária 13.415/17 que alterou a Lei de Diretrizes e Bases da Educação no 9.394/96, com inúmeras implicações tanto estruturais (curricular), quanto materiais (formacional); e revogou a Lei do Espanhol, único instrumento legal no território brasileiro a velar pela propagação, necessária, de um dos idiomas oficiais do Mercosul. Observa-se que no grupo dos países que compõem o Mercosul, o Brasil, única nação que desestimulou violentamente a quebra de barreiras linguísticas que objetiva a integração desses países, distanciou-se do alcance de um dos objetivos do Bloco Econômico, que é a oferta das línguas portuguesa e espanhola no ensino formal para a aproximação econômica, política, cultural, linguística e social dos membros oficiais.

Dessa maneira, faz-se necessário que os cursos de formação de professores de espanhol no território brasileiro aprofundem essas questões, para que, ao optar por determinada variedade, ou até mesmo uma mescla da língua espanhola de algumas regiões, o educador possa fazê-lo de maneira consciente, levando em consideração as reais motivações e necessidades de seus alunos.

O professor de espanhol como língua estrangeira, especialmente os inseridos no contexto brasileiro, não pode ignorar os americanismos (como o uso recorrente do voseo) em suas aulas. Considerar e levar a variação linguística, em um contexto multi e intercultural, para a sala de aula se faz essencial para que o aluno possa utilizar a língua de forma coerente e contextualizada, principalmente conhecendo a proximidade existente entre o Brasil e os países hispano-americanos e a frequência em que há intercâmbios entre eles. 


\section{Referências}

AGOSTO, S. E. El español, uno $y$ diverso. Disponível em: http://www.unidadenladiversidad.com/opinion/opinion_ant/2006/nov_dec_06/opiniodic _06.htm. Acesso em: 20 out. 2018.

ANDIÓN HERRERO, M. A. La diversidad lingüística del español: la compleja relación entre estándar, norma y variedad. Disponível em: http://www.lllf.uam.es/clg8/actas/pdf/paperCLG10.pdf. Acesso em: 10 set. 2018.

BRASIL. M. E. Orientações Curriculares Nacionais para o Ensino Médio (OCEM), Conhecimentos de Espanhol. Brasília: Secretaria de Educação Básica, capítulo 4, p.127$164,2006$.

BUGEL, T. O Espanhol na cidade de São Paulo: quem ensina qual variante a quem? Trabalhos de Linguística Aplicada, Campinas, SP, n. 33, p. 169-182, 1999.

BUGEL, T; SANTOS, H. S. As atitudes e representações do espanhol no Brasil e a expansão das Indústrias da língua no país, 2007.

FONTANELlA DE WEINBERG, M. B. El español de América. 2. ed., Madrid: Mapfre, 1993.

GUERRERO RUIZ, P. El español como lengua extranjera: hacia una Pedagogía de la Interculturalidad. Disponível em: http://www.unidadenladiversidad.com/opinion/opinion_ant/2004/octubre_2004/opinion_14100 4.htm. Acesso em: 15 set. 2018.

IRALA, V. A opção da variedade de Espanhol por professores em serviço e pré-serviço, Linguagem \& ensino, São Paulo, n. 2, p. 99-120, 2004.

LOPE BLANCH, J. M. Estudios de Lingüística Hispanoamericana. Ciudad de México: Universidad Nacional Autónoma de México, 1989.

MORENO FERNÁNDEZ, F. Qué español enseñar. Madrid: Arco Libros, 2000.

MURGA, M. H. As atitudes de estudantes de E/LE com relação às variedades diatópicas do espanhol. Dissertação (mestrado em Linguística Aplicada), departamento de Línguas Estrangeiras e Tradução da Universidade de Brasília, Brasília, DF, 2007.

SANTOS, A. G. A variação da língua espanhola num curso de formação de professores de E/LE no Brasil. Dissertação (mestrado em Língua e Cultura), Instituto de Letras da Universidade Federal da Bahia, Salvador, BA, 2016.

ZOLIN-VESZ, F. A Espanha como o único lugar que se fala a língua espanhola - a quem interessa essa crença? In: Zolin-Vesz, F. (Org.). A (In)visibilidade da América Latina no Ensino de Espanhol, Campinas, SP: Pontes, p. 51-62, 2013.

Recebido em: 31 jan. 2019.

Aceito em: 11 abr. 2019. 